\title{
УДОСКОНАЛЕННЯ ПРОЦЕСУ ПРОСУВАННЯ МІЖНАРОДНИХ ТРАНЗИТНИХ ПОЇЗДІВ ЗАЛІЗНИЦЯМИ УКРАЇНИ
}

\author{
Представив д-р техн. наук, професор С.С. Альоиинський
}

Вступ. Україна є активним учасником глобальної та регіональної економічної діяльності. Вона має винятково вигідне, можна без перебільшення сказати, унікальне географічне положення - якраз на шляху значних транзитних товаропотоків між Азією та Європою, Північчю та Півднем. Наявність розгалуженої транспортної мережі як у широтних, так і в меридіанних напрямках, за умов активної зовнішньоекономічної діяльності, перетворює нашу державу на одну 3 провідних транзитних на всьому євразійському просторі. Потенціал розширення $\mathrm{CC}$ та заходи щодо формування єдиного економічного простору стимулюють Україну до реалізації свого потужного транзитного потенціалу.

Актуальність. У загальному обсязі вітчизняного експорту послуг транспортні займають 65,2\%, або 7,62 млрд. дол. США, що становить 2,67\% ВВП України. Вартість основних виробничих фондів транспортної галузі дорівнює $12,3 \%$ від загальної вартості всіх виробничих фондів нашої держави. У транспортному комплексі зайнято $5,6 \%$ усіх працюючих у господарстві країни. Транспорт споживає близько $10 \%$ від загального обсягу енергоресурсів, спожитих в Україні за рік. Найбільшу частку у міжнародному продуктообміні через українську транспортну мережу мають сировинні вантажі: нафта, нафтопродукти, газ, аміак, чорні метали, зерно. У загальному обсязі експортних транспортних послуг, які реалізуються транспортною мережею України, залізничний транспорт посідає друге місце після трубопровідного i перевозить близько третини всіх транзитних вантажів, реалізуючи обсяг транспортних послуг більш ніж на 1,6 млрд дол. США.

Однак незважаючи на значні обсяги перевезень у даний час Україна починає поступатися позицією лідера транзитних перевезень на напрямку Західно-Східна Свропа - Азія сусіднім державам конкурентам, зокрема Білорусі, Польщі, Росії. Це відбувається здебільшого через низькі темпи розвитку внутрішньодержавної системи транзитних перевезень, недостатній розвиток мережі шляхів, прямування віднесених до міжнародних транспортних коридорів, низькі швидкості просування транзитних поїздів та значні затримки міжнародних составів на прикордонних передавальних станціях у процесі реалізації технології передавання составів за кордон. Це призводить до значних збільшень строків доставки вантажів та затягування процесів просування транзитних міжнародних поїздів залізницями України, що поступово формує негативний імідж залізниць України та їх транзитного потенціалу.

Постановка завдання. Отже, враховуючи зазначені проблеми міжнародних транзитних перевезень залізниць України в сучасних умовах, необхідним $€$ першочергове вирішення проблеми швидкості просування міжнародних транзитних поїздів 
залізницями України. Вирішення цього завдання потребує винайдення раціональних рішень щонайменше у двох напрямках - удосконалення технологічного процесу організації передачі міжнародних поїздів за кордон на прикордонних передавальних станціях та розробки заходів підвищення ефективності планування маршрутів просування міжнародних составів. Вирішення першого завдання пов'язане 3 необхідністю перегляду технологічного процесу роботи окремої передавальної станції та пошуком після цього можливих варіантів скорочення часу на технологічні операції, що складно здійснити без аналізу конкретної станції. Вирішення другого завдання $є$ більш загальним i пов'язане 3 необхідністю формування оперативної системи розробки раціональних маршрутів прямування міжнародних транзитних поїздів.

В сучасних умовах розвитку інформаційних технологій створення оперативної системи формування маршрутів потребує розробки та впровадження системи підтримки прийняття рішень (СППР), спрямованої на підтримку оперативного персоналу стосовно автоматизації процесу прийняття оперативних рішень на всіх рівнях управління.

Аналіз останніх досліджень. Результати отриманих експериментальних даних в [1] показали ефективність використання нейро-нечіткого моделювання при створенні СППР для оперативного регулювання маршрутів у приміському сполученні. Розробка на основі досвіду [1] моделі оперативного формування та регулювання маршрутів міжнародних транзитних поїздів дозволить створити якісну основу для подальшого створення СППР у вигляді програмного комплексу на автоматизованому робочому місці працівника оперативного персоналу.

Основний матеріал. Запропонований метод проектування математичної моделі оперативного формування та регулювання маршрутів прямування дозволяе, використовуючи нелінійні принципи, представляти експертні висновки за допомогою правил, а існуюча гібридна технологія адаптивних нейро-нечітких систем висновків ANFIS (Adaptive Networkbaset Fuzzy Interference System) дає можливість автоматизувати процес настроювання моделі [4].

Отже, враховуючи головне завдання визначення найбільш оптимального маршруту прямування 3 найменшими витратами часу на рух можливі варіанти вирішення задачі залежать від двох основних параметрів - резерв пропускної спроможності відповідно до графіка руху поїздів (ГРП) деякої дільниці $\Delta N^{A B}$ та витрат часу на прямування міжнародного транзитного поїзда по деякій дільниці А-В $t_{j j}^{A B}$, врахованих від моменту прибуття на деяку станцію подальшого відправлення А до моменту прибуття на деяку наступну станцію $\mathrm{B}$, що відображає швидкість обробки поїзда по станції А, час очікування відправлення на В, особливість профілю дільниці А-B та середню можливу швидкість руху по дільниці.

Перший вхідний параметр моделі визначається як рівень можливого об'єму руху, що можливо реалізувати на деякій дільниці А-В понад фактичні розміри, що визначається різницею між пропускною спроможністю деякої дільниці А-В та фактичними розмірами руху

$$
\begin{aligned}
& \Delta N^{A B}=N^{A B}-P^{A B} ; \\
& P^{A B}=\sum_{i, j=1}^{m} P_{i j}^{A B} ; \\
& N^{A B}=\frac{\alpha_{u} \cdot\left(1440-T_{b}\right)}{T_{n e p}},
\end{aligned}
$$

де $N^{A B}$ - пропускна спроможність деякої дільниці А-B; 
$P^{A B}$ - фактичні розміри руху деякої дільниці А-B;

$P_{i j}^{A B}$ - певна нитка ГРП з відправленням з А у $i$-й час та прибуттям на В у $j$-й;

$m$ - кількість ниток ГРП, прокладених на дільниці А-В за добу;

$\alpha_{н}$ - коефіцієнт надійності, що враховує можливі порушення в системі руху поїздів;

$T_{в}$ - час на виконання операцій утримання споруд та пристроїв перегону в умовах надання вікна, хв;

$T_{n e p}$ - період графіка руху поїздів на деякій дільниці А-В.

Другий вхідний параметр моделі визначається як рівень витрат часу на прямування, які будуть здійснені на деякій дільниці А-В при проходженні поїзда від моменту прибуття на деяку станцію А до відправлення 3 неї та при прямуванні по дільниці до наступної деякої станції В у найбільш сприятливих умовах

$$
t_{j j}^{A B}=t_{j}^{A}+t_{o}^{A}+t_{i}^{A}+\sum_{n=1}^{k} \frac{l_{n}^{A B}}{v_{n}^{A B}}
$$

де $l_{n}^{A B}$ - відстань $n$-ї частини дільниці А-В, яку поїзд проходить без зміни швидкості, КМ;

$v_{n}^{A B}$ - швидкість, з якою поїзд проходить $n$-у частину дільниці А-В від моменту однієї ії зміни до моменту наступної зміни, км/год;

$k$ - кількість разів зміни швидкості при прямуванні поїзда дільницею А-В.

При цьому доцільним $є$ урахування додаткових факторів впливу на систему вхідних параметрів, які можуть вплинути на правильність прийняття оперативного рішення. Тому необхідним $є$ формування системи обмежень:

1. Для забезпечення пропуску поїздів по деякій дільниці А-В без перешкод та затримок через значну напруженість руху пропускна спроможність має перевищувати фактичні розміри руху дільниці

$$
N^{A B}>P^{A B}
$$

2. Вибір для подальшого прямування на кожному етапі деякої А-В дільниці 3 мінімальним часом руху буде доцільним, якщо загальний час проходження маршруту буде мінімальний

$$
T=\sum_{r=1}^{k^{A B}} t_{r}^{A B} \Rightarrow \min
$$

де $T-$ загальний час прямування залізницями України певного міжнародного транзитного поїзда;

$k^{A B}$ - кількість деяких $r$-х дільниць А-В на шляху прямування залізницями України певного міжнародного транзитного поїзда.

3. Доцільність відправлення кожного певного поїзда саме на деяку дільницю А-В матиме місце лише при наявності вільної нитки ГРП на момент закінчення обробки міжнародного транзитного состава, 3 можливістю додавання незначного часу ii очікування, у порівнянні 3 іншою можливою деякою дільницею прямування E-H, що буде характеризувати міру інерційності системи

$$
t_{j j}^{A B}= \begin{cases}1, & \text { якщฺ } t_{j j}^{A B}+\Delta t^{A B}<t_{j j}^{E H} \Delta t^{E H} \\ 0, & \text { якщ̧о } t_{j j}^{A B}+\Delta t^{A B}>t_{j j}^{E H} \Delta t^{E H},(7)\end{cases}
$$

де $\Delta t^{A B}, \Delta t^{E H}$ - час очікування вільної нитки ГРП при відправленні на дільницю A-В чи Е-Н.

4. На кожному наступному кроці при переході з однієї дільниці прямування на іншу до системи відбору наступної дільниці мають обиратися лише дільниці того ж напрямку (парного чи непарного).

Таким чином, відповідно до обмежуючих умов у систему відбору 
дільниць прямування на кожному етапі формування маршруту будуть включатися лише ті, що відповідають зазначеним вимогам. Це дозволить спростити процес перебору та оцінки кожної наступної дільниці прямування та підвищити швидкість роботи системи винайдення маршрутів.

Отже, запропонована модель може розглядатися як система 3 двома входами $X\left(\Delta N^{A B}, t_{i j}^{A B}\right) \quad$ та одним дискретним виходом $D=\left\{d_{1}, d_{2}, \ldots, d_{k}\right\}, \quad$ де $d_{k}(k=\overline{1, N)}$ дискретні значення, що відповідають одному 3 рівнів прийняття рішень.

Таким чином, задача розробки відповідних рішень для оперативного регулювання композиції состава полягає у виконанні відображення

$X=\left(\Delta N^{A B}, t_{i j}^{A B}\right) \rightarrow D \in\left\{d_{1}, d_{2}, \ldots, d_{k}\right\}$

де $d_{1}$ - доцільність призначення $100 \%$;

$d_{2}$ - доцільність призначення 87,5\%;

$d_{3}$ - доцільність призначення $75 \%$;

$d_{4}$ - доцільність призначення $62,5 \%$;

$d_{5}$ - доцільність призначення 50\%.

$d_{6}$ - доцільність призначення $37,5 \%$;

$d_{7}$ - доцільність призначення $25 \%$;

$d_{8}$ - доцільність призначення $12,5 \%$;

$d_{9}$ - доцільність призначення $0 \%$.

Опишемо вхідні параметри $X$ відповідними нечіткими лінгвістичними змінними (ЛЗ) [1], які представляють кортеж такого виду $\left\langle N_{i}, T_{i}, X_{i}\right\rangle$, де $N_{i}-$ назва ЛЗ; $T_{i}$-терм-множина ЛЗ $N_{i}$ або множина ії значень (термін), кожний з яких являє собою найменування окремої нечіткої змінної $\alpha_{j}^{i}(j=\overline{1, m})$, що визначена $\mathrm{y}$ вигляді кортежу $\left\langle\alpha_{j}^{i}, X_{i}, \tilde{A}_{j}^{i}\right\rangle$, в якому нечітка підмножина $\tilde{A}_{j}^{i}$ базової множини $X_{i}$ описує можливі значення, що може приймати нечітка змінна $\alpha_{j}^{i}$

$$
\widetilde{A}_{j}^{i}=\left\{\left\langle x, \mu_{\tilde{A}_{j}^{i}}(x) \mid X_{i}\right\rangle\right\}
$$

де

$$
\mu_{\tilde{A}_{j}^{i}}: X_{i} \rightarrow[0,1] \quad-\quad \text { функція }
$$

приналежності нечіткої підмножини $\tilde{A}_{j}^{i}$, яка ставить у відповідність кожному елементу $x \in X_{i}$ число з інтервалу[0,1], що представляє ступінь приналежності елемента $x$ підмножині $\tilde{A}_{j}^{i}$.

Як вхідні параметри нечіткої моделі будемо розглядати дві нечіткі Л3: $N_{1}=\Delta N^{A B}=\ll$ Резерв пропускної спроможності деякої дільниці А-В», $N_{2}=t_{j j}^{A B}=$ «Витрати часу на проходження деякої дільниці А-В». Формалізацію нечітких термів у роботі здійснено за допомогою моделей функцій приналежності (ФП), параметри яких можуть модифікуватися в процесі настроювання моделі, що дозволяє змінювати положення та структуру нечітких множин $[1,2,3]$.

Значення першої ЛЗ $\triangle N^{A B}$ визначаємо 3 терм-множини $T_{1}=\{$ «високий»(В), «середній» $(\mathrm{C})$, «низький» $(\mathrm{H})\}$. Для терма «С» запропоновано використовувати ФП, що формується 3 використанням кусковолінійної апроксимації та має трикутну структуру. Крайні терми «В» та «Н» описуються ФП, яка має трапецієподібну структуру, відповідно відкриту ліворуч та праворуч $[1,2,3]$.

Другу Л3 $t_{j j}^{A B}$ опишемо за допомогою терм-множини $\quad T_{2}=\{$ «вище за оптимальні»(ВО), «оптимальні»(О), «нижче за оптимальні»(HO) $\}$. Нечіткий терм «О» представлений за допомогою ФП 
симетричного гаусового типу. Для крайніх термів лінгвістичної змінної «ВО» та «НО» ФП формуються на основі поліноміальних кривих. Приймаємо для термів «НО» та «ВО» відповідно Z-подібну ФП, що являє собою асиметричну поліноміальну криву, відкриту ліворуч, та S-подібну ФП, яка $\epsilon$ дзеркальним відображенням функції Z $[1,2,3]$.

Нечітку лінгвістичну інформацію можна представити у вигляді правил у формі нечітких умовних суджень типу «Якщо ..., то», де перша частина правила містить набір умов, а друга $\epsilon$ наслідком, що містить висновок. У гібридній системі можливим $\epsilon$ використання нечіткої бази правил типу Сугено 1-го порядку [3]. В цьому випадку правило $r_{k}$ для змінних $X_{i}$ можна зобразити у такому вигляді:

$$
\begin{array}{r}
r_{k}: \text { якщо } X_{1} є a_{1}^{k} \perp X_{2} є a_{2}^{k}, \text { то } \\
d_{k}=m_{0, k}+b_{1, k} \cdot X_{1}+b_{2, k} \cdot X_{2},
\end{array}
$$

де $r_{k}$ - нечітке правило за порядковим номером $k, k=\overline{1, N}$;

$X_{i}$ - відповідні нечіткі Л3;

$a_{i}^{k}$ - нечіткий терм з ФП $\mu_{A}^{k}\left(X_{i}\right)$, що застосовується для оцінки лінгвістичної змінної $X_{i} \quad$ у $k$-му правилі $(k=\overline{1, N}, i=\overline{1, n})$;

$d_{k}$ - висновок кожного правила, що являє чітку лінійну функцію, представлену як поліном першого порядку 3 коефіцієнтами $b_{1, k}, \ldots, b_{q, k}(q=\overline{1, n}, k=\overline{1, N}) \quad$ та вільною складовою $m_{0, k}$; або.

$\perp-$ операція логічного зв'язування $m a$,

Основою для формування нечітких правил є експертні судження щодо вибору варіанта дій при певному співвідношенні вхідних параметрів. Тому згідно 3 вищезазначеним підходом на основі експертного аналізу та розробки відповідних практичних рішень щодо вибора оптимального варіанту маршруту було розроблено систему нечітких правил:

$$
r_{1} \text { : Якщо } \Delta N^{A B} \epsilon \text { "В" ma } t_{j j}^{A B} \epsilon
$$
"HO", mo d $d_{1}$;

$$
r_{2} \text { : Якщо } \Delta N^{A B} \epsilon \text { "В" ma } t_{j j}^{A B} \epsilon
$$

"O", mo $d_{2}$;

$$
r_{3} \text { : Якщо } \Delta N^{A B} \epsilon \text { “C" ma } t_{j j}^{A B} \epsilon
$$
"HO", mo d d $_{3}$

$$
r_{4} \text { : Якщо } \Delta N^{A B} \epsilon \text { “C” ma } t_{j j}^{A B} \epsilon
$$
"O", $\mathrm{mo} \mathrm{d}_{4}$;

$$
r_{5} \text { : Якщо } \Delta N^{A B} \epsilon \text { " } \mathrm{H} \text { " ma } t_{j j}^{A B} \epsilon
$$
"HO", $\operatorname{mo~}_{5}$;

$$
r_{6} \text { : Якщо } \Delta N^{A B} \epsilon \text { "H" ma } t_{j j}^{A B} \epsilon
$$

“O”, mo $d_{6}$;

$$
r_{7} \text { : Якщо } \Delta N^{A B} \epsilon \text { "В" або } t_{j j}^{A B} \epsilon
$$
“BO", mo d $d_{7}$;

$$
r_{8} \text { : Якщо } \Delta N^{A B}{ }_{\epsilon} \text { "C" або } t_{j j}^{A B} \epsilon
$$
"BO", mo d $d_{8}$;

$r_{9}$ : Якщо $\Delta N^{A B} \epsilon$ "H” або $t_{j j}^{A B} \epsilon$ “BO", mo d $d_{9}$.

Наступним кроком побудови моделі $\epsilon$ реалізація запропонованої системи нечітких правил на основі штучної нейронної мережі. Аналогічно, як i в [1], використаємо п'ятишарову нейронну мережу прямонаправленої архітектури 3 використанням «логічних нейронів» (maнейронів) $[3,4]$, що моделюють логічні зв'язування. Отже, у процесі функціонування нечітка мережа являє 
собою структуру, що складається із п'яти спеціалізованих шарів.

Кожен нейрон першого шару $\epsilon$ радіальним базисним нейроном, що перетворює значення вхідної змінної $X_{i}, i=1,2$ за допомогою відповідної ФП $\mu_{A}^{k}\left(X_{i}\right)$ у відповідний нечіткий терм. Це параметричний шар, в якому параметри ФП підлягають адаптації в процесі навчання [1].

В другому шарі кожен нейрон моделює відповідний логічний зв'язок i посилає на вихід активуючу силу правила, тобто ваги $w_{k}$. Це непараметричний шар [1].

Для моделювання логічного оператора ma використовується нечіткий нейрон, в якому вхідні сигнали $X_{i}$ взаємодіють 3 вагами $w_{i}$, утворюючи добуток, який реалізується за допомогою трикутної t-конорми $S$, що представлена алгебраїчною сумою: $p=S\left(w_{i}, X_{i}\right)$, тоді як добуток об'єднується 3 використанням операції підсумовування на основі трикутної t-норми $T-$ алгебраїчний добуток, що являє собою вхід $N$ нейрона: $N=T\left(w_{i}, X_{i}\right)[1]$.

Перетворення потенціалу, здійснюване нечітким нейроном із двома входами, має вигляд

$$
y=F(N)=T\left(S\left(w_{1}, X_{1}\right), S\left(w_{2}, X_{2}\right)\right) .
$$

Таким чином, ваги визначаються нечіткою логічною операцією $m a$ як добуток - $w_{k}=\mu_{A_{i}}^{k}\left(X_{1}\right) \cdot \mu_{A_{i}}^{k}\left(X_{2}\right)$ [1].

Неадаптивні вузли третього шару обчислюють нормовану силу правила [1]

$$
\bar{w}_{k}=w_{k} / \sum_{i=1}^{9} w_{k} .
$$

Четвертий шар з'єднаний 3 третім шаром та $з$ усіма входами мережі. В ньому розраховується внесок одного нечіткого правила у вихід мережі

$$
\bar{w}_{k} d_{k}=\bar{w}_{k}\left(m_{0, k}+b_{1, k} \cdot X_{1}+b_{2, k} \cdot X_{2}\right)
$$

Це параметричний шар, у якому адаптації підлягають лінійні параметри $m_{0, k}, b_{1, k}, \ldots, b_{q, k}$ для $\quad(q=\overline{1, n}, k=\overline{1, N})$, які визначають функції наслідків правил [1].

В останньому, п'ятому шарі ваги піддаються нормалізації й обчислюється вихідний сигнал $d$ відповідно до виразу (14). Це також непараметричний шар [1].

$$
d=\sum_{k=1}^{9} \bar{w}_{k} d_{k}=\frac{\sum_{k=1}^{9} w_{k} d_{k}}{\sum_{k=1}^{9} w_{k}}
$$

Результат розробки нейро-нечіткої моделі подано на рис. 1 у вигляді мережі ANFIS.

Для навчання нейро-нечіткої мережі в роботі пропонується використовувати гібридний метод для настроювання параметрів ФП, завдяки чому оцінюються коефіцієнти висновків правил [5,1]. Для цього було сформовано навчальну вибірку iз 90 експериментальних даних у вигляді $<$ вхід $\left(\Delta N^{A B}, t_{i j}^{A B}\right)-$ вихід $\left(d_{k}\right)>$. На рис. 2 наведено криву навчання моделі ANFIS y вигляді залежностей похибок навчання від кількості ітерацій алгоритму. Мінімум похибки навчання складає $0,35221 \%$ та досягається в районі 61-ї ітерації алгоритму. Після 61-ї ітерації похибка стає сталою, що вказує на втрату моделлю властивостей узагальнення. 


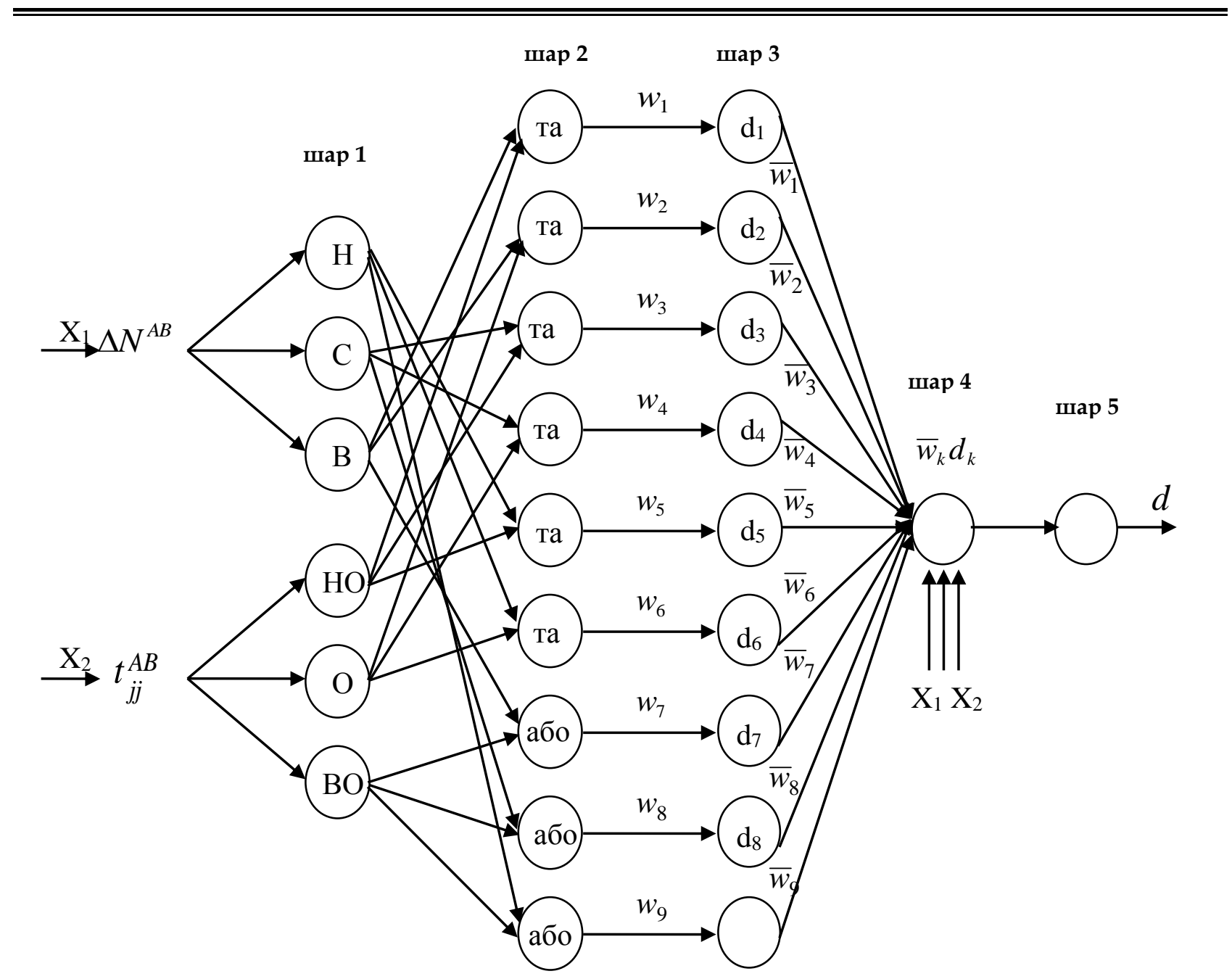

Рис. 1. Нейро-нечітка структура мережі ANFIS

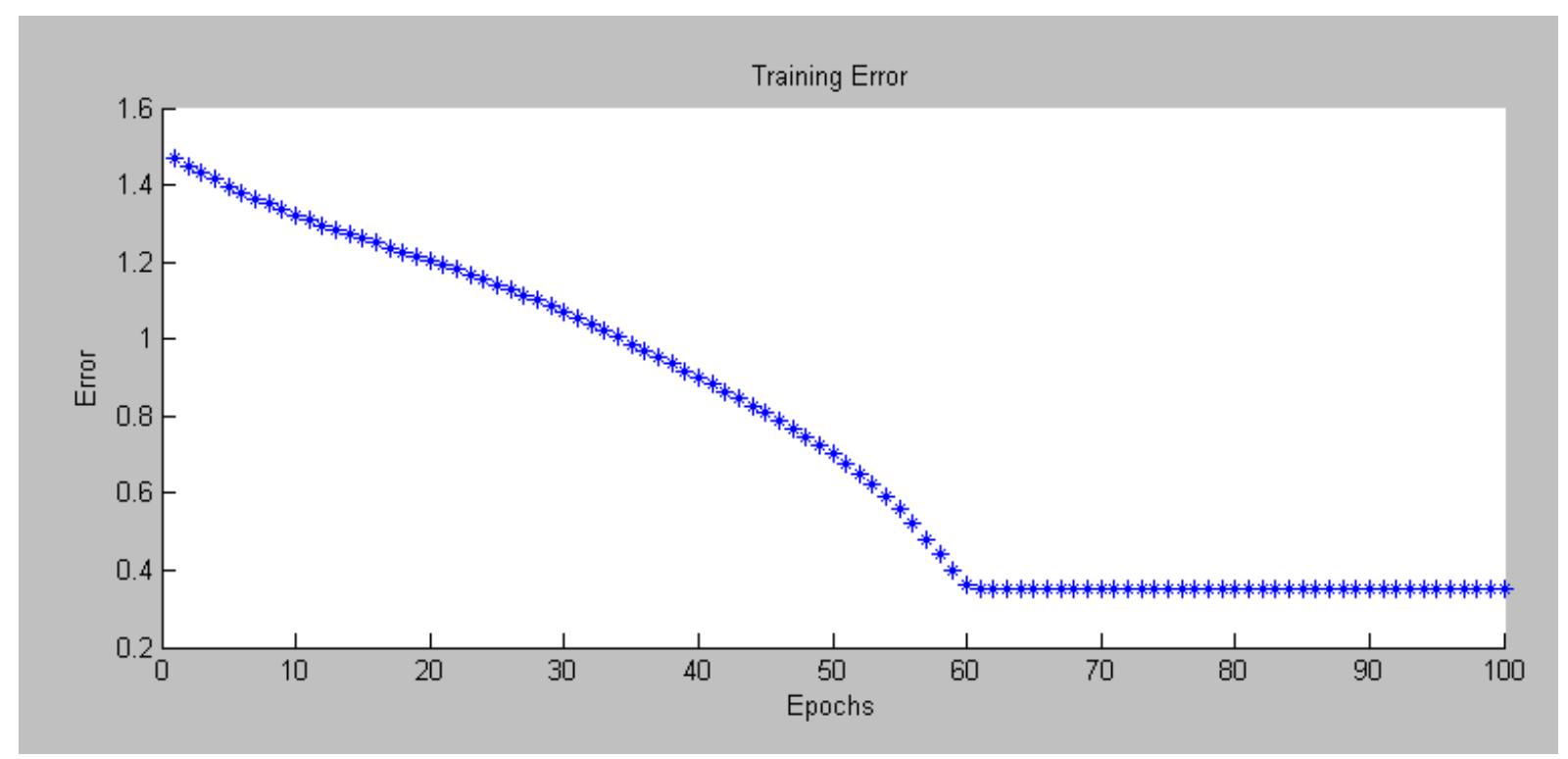

Рис. 2. Крива навчання моделі ANFIS 
Результатом розробки моделі $є$ проведення іiі тестування на тестовій вибірці. На рис. 3 подано результати тестування моделі після навчання у вигляді ступеня точності потрапляння значення виходу до області певного варіанта рішення.

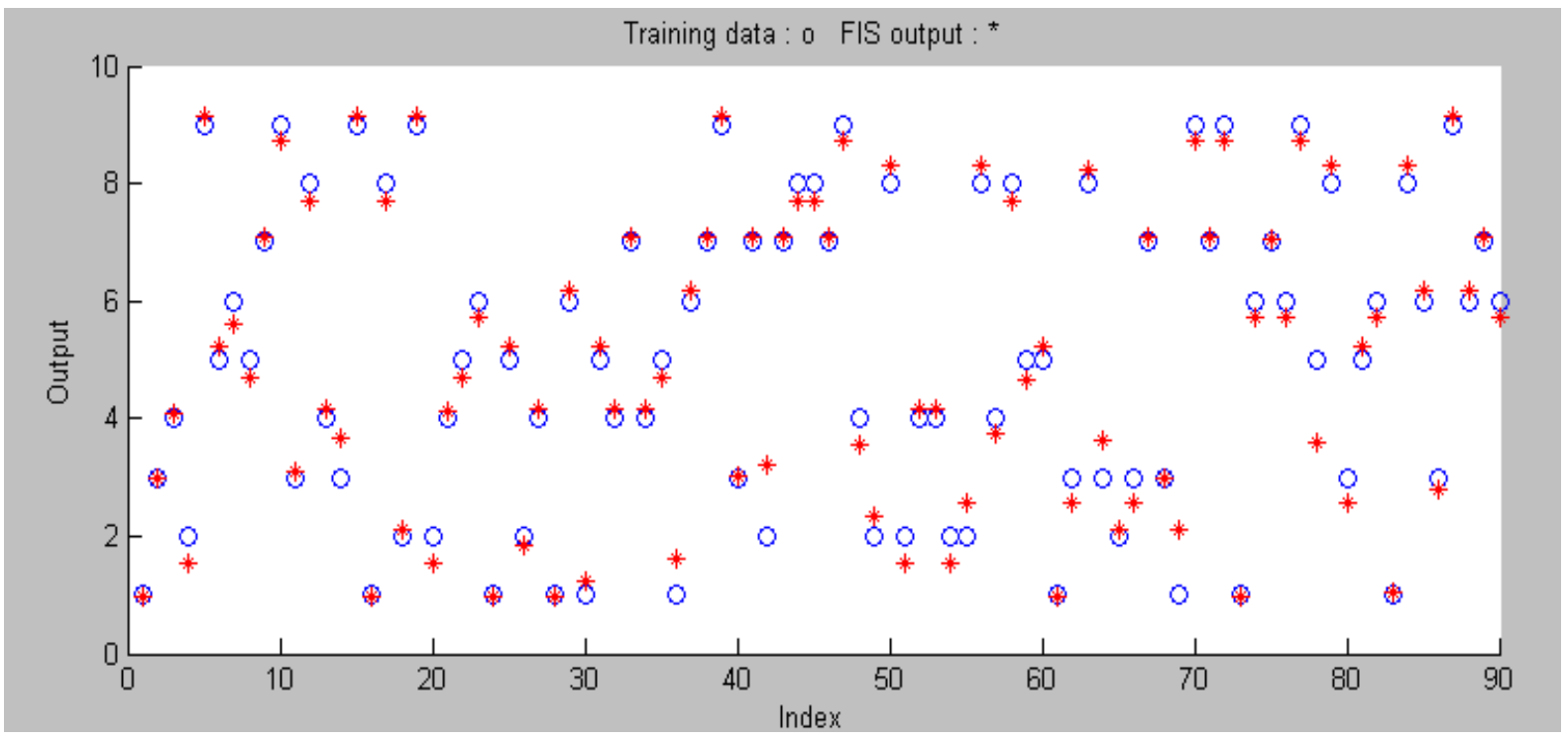

Рис. 3. Результати тестування моделі ANFIS

Аналіз результатів тестування вказує на досить високий рівень точності роботи тренованої моделі, мінімальний рівень похибки якої не перевищує $0,35 \%$, а загальний $-5 \%$. Висока точність роботи зберігається приблизно близько 42 ітерацій, після чого спостерігається втрата точності в певних варіантах рішення, що потребує подальшого навчання моделі на нових даних. Подальше підвищення якості роботи моделі може бути досягнуто доопрацюванням при впровадженні i експлуатації іiі на практиці, та адаптації до фактичних реальних умов праці.

Висновок. Впровадження на основі запропонованої моделі системи формування та регулювання маршрутами прямування міжнародних транзитних поїздів дозволить якісно удосконалити систему організації обслуговування міжнародного транзитного вагонопотоку 3 можливістю подальшого формування СППР у вигляді програмного комплексу на АРМ оперативних працівників. Це дозволить автоматизувати процес управління просуванням міжнародних поїздів залізницями України та скоротити терміни передачі їх за кордон, що в свою чергу дозволить сформувати позитивний імідж залізниць України на ринку міжнародних транспортних послуг.

\section{Список літератури}

1. Константінов, Д.В. Моделювання оперативного регулювання маршрутами приміського руху на основі нечіткої логіки та нейронних мереж [Текст] / Д.В. Константінов, Т.В. Бутько // Інформаційно-керуючі системи на залізничному транспорті. - 2010. - №1(80). - C. 13-19.

2. Борисов, А.Н. Модели принятия решений на основе лингвистической переменной [Текст] / А.Н. Борисов, А.В. Алексеев, О.А. Крумбург. - Рига: Зинантне, 1989. 
3. Ярушкина, Н.Г. Основы теории нечетких и гибридных систем [Текст]: учеб. пособие / Н.Г. Ярушкина. - М.:Финансы и статистика, 2004. - 320 с.

4. Jang J.-S. R. "ANFIS:Adaptive-Network-Based Fuzzy Inference System" // IEEE Trans. Systems \& Cybernetics. - 1993. - Vol. 23. - P. 665-685.

5. Ротштейн, А.П., Soft Computing: идентификация закономерностей нечеткими базами знаний [Текст] / А.П. Ротштейн, Ю.И. Митюшкин / Винницкий гос. техн. ун-т. - Винница: Универсум-Винница, 2002. - 145 с.

Ключові слова: міжнародні перевезення, транзитні поїзди, регулювання, маршрути, система підтримки прийняття рішень, моделювання.

\section{Анотаціi}

У статті розглянуто питання удосконалення системи пропуску міжнародних транзитних поїздів по залізницях України. Представлено модель системи підтримки прийняття рішень, призначеної для визначення найкращого напрямку прямування міжнародного транзитного поїзда зі станції обробки. Модель розроблено на основі математичних апаратів нечіткої логіки та нейронних мереж.

В статье рассмотрен вопрос усовершенствования системы пропуска международных транзитных поездов по железным дорогам Украины. Представлена модель системы поддержки принятия решения, предназначенной для определения наилучшего направления следования международного транзитного поезда со станции обработки. Модель разработана на основе математических аппаратов нечеткой логики и нейронных сетей.

In the article the question of improving the system passes international transit trains on the railways of Ukraine. The model of decision support system designed to determine the best course of following the international transit train from treatment. The model is developed on the basis of mathematical apparatus of fuzzy logic and neural networks. 